\title{
Vasodilatory Responses of Renal Interlobular Arteries to Epoxyeicosatrienoic Acids Analog Are Not Enhanced in Ren-2 Transgenic Hypertensive Rats: Evidence Against a Role of Direct Vascular Effects of Epoxyeicosatrienoic Acids in Progression of Experimental Heart Failure
}

\author{
A. SPORKOVÁ ${ }^{1}$, Z. HUSKOVÁ ${ }^{1}$, P. ŠKAROUPKOVÁ ${ }^{1}$, N. RAMI REDDY ${ }^{2}$, J. R. FALCK ${ }^{2}$, \\ J. SADOWSKI ${ }^{3}$, L. ČERVENKA ${ }^{1,4}$ \\ ${ }^{1}$ Center for Experimental Medicine, Institute for Clinical and Experimental Medicine, Prague, \\ Czech Republic, ${ }^{2}$ Department of Biochemistry, University of Texas Southwestern Medical Center, \\ Dallas, Texas, USA, ${ }^{3}$ Department of Renal and Body Fluid Physiology, Mossakowski Medical \\ Research Centre, Polish Academy of Science, Warsaw, Poland, ${ }^{4}$ Department of Pathophysiology, \\ Second Faculty of Medicine, Charles University, Prague, Czech Republic
}

Received March 15, 2016

Accepted June 21, 2016

On-line October 26, 2016

\section{Summary}

Pathophysiological mechanisms underlying the development of renal dysfunction and progression of congestive heart failure (CHF) remain poorly understood. Recent studies have revealed striking differences in the role of epoxyeicosatrienoic acids (EETs), active products of cytochrome P-450-dependent epoxygenase pathway of arachidonic acid, in the progression of aorto-caval fistula (ACF)-induced CHF between hypertensive Ren-2 renin transgenic rats (TGR) and transgene-negative normotensive Hannover Sprague-Dawley (HanSD) controls. Both ACF TGR and ACF HanSD strains exhibited marked intrarenal EETs deficiency and impairment of renal function, and in both strains chronic pharmacologic inhibition of soluble epoxide hydrolase (sEH) (which normally degrades EETs) normalized EETs levels. However, the treatment improved the survival rate and attenuated renal function impairment in ACF TGR only. Here we aimed to establish if the reported improved renal function and attenuation of progression of CHF in ACF TGR observed after SEH blockade depends on increased vasodilatory responsiveness of renal resistance arteries to EETs. Therefore, we examined the responses of interlobar arteries from kidneys of ACF TGR and ACF HanSD rats to EET-A, a new stable 14,15-EET analog. We found that the arteries from ACF HanSD kidneys rats exhibited greater vasodilator responses when compared to the ACF TGR arteries. Hence, reduced renal vasodilatory responsiveness cannot be responsible for the lack of beneficial effects of chronic $\mathrm{SEH}$ inhibition on the development of renal dysfunction and progression of CHF in ACF HanSD rats.

\section{Key words}

Congestive heart failure - Aorto-caval fistula • Epoxyeicosatrienoic acids • Hypertension

\section{Corresponding author}

L. Červenka, Department of Pathophysiology, Second Faculty of Medicine, Charles University, Prague, Czech Republic. E-mail: luce@medicon.cz

\section{Introduction}

Congestive heart failure (CHF) is a major public health problem affecting currently $4 \%$ of the adult population in Europe and the yearly increase in the number of new patients is estimated at $50 \%$ (Braunwald 2015a, Maggioni 2015). The patients' survival rate is worse than in most types of cancers, especially in cases associated with impairment of renal hemodynamics and sodium retention (Braam et al. 2014, Braunwald 2015a) hypertension and renal dysfunction are independent crucial risk factors for the progression of $\mathrm{CHF}$ (Braam et 
al. 2014, Mann and Bohm 2015). Obviously, new treatment strategies are urgently needed (Braam et al. 2014, Braunwald 2015b, Iwaz et al. 2016). However, the prerequisite for successful treatment is a better understanding of the pathophysiology of renal dysfunction in CHF.

Increased activity of the renin-angiotensin system (RAS) was previously shown to be crucial for the development of renal dysfunction and progression of CHF (Braunwald 2015b, Cohen-Segev et al. 2014, Ichikawa et al. 1984, Packer 1996, Pfeffer et al. 1985), however, it cannot be the sole causative factor. It has been proposed that intrarenal interaction between RAS and other vasoactive system(s) is important (Abassi et al. 2011, Braam et al. 2014). Attention was focused on epoxyeicosatrienoic acids (EETs), metabolites of cytochrome P-450 (CYP) dependent epoxygenase pathway of arachidonic acid metabolism known to participate in the regulation of cardiovascular and renal function (Capdevila et al. 2015, Elmarakby 2012, Fan et al. 2015, Neckáŕ et al. 2012, Sporková et al. 2011, Walkowska et al. 2010). EETs induce arterial dilatation directly through activation of large-conductance calciumactivated potassium channels and reduction of calcium entry into vascular smooth muscle cells, and also by opposing renal vasoconstrictor actions of angiotensin II (ANG II) (Imig and Deichmann 1997, Imig et al. 2001, Kohagure et al. 2000). EETs also inhibit tubular sodium reabsorption and induce natriuresis (Madhun et al. 1991, Sakairi et al. 1995,). These results led to a proposal that intrarenal EETs counteract increased RAS activity (Elmarakby 2012, Fan et al. 2015, Imig et al. 2001). Thus, increasing the tissue bioavailability of EETs could become a new approach to combat renal dysfunction and progression of CHF. This is commonly achieved by blocking soluble epoxide hydrolase $(\mathrm{sEH})$, the enzyme which degrades EETs to biologically inactive dihydroxyeicosatrienoic acids (DHETEs) (Capdevila et al. 2015, Elmarakby 2012, Fan et al. 2015). Since augmentation of tissue EETs' bioavailability proved antihypertensive and nephro- and cardioprotective, we reasoned that chronic $\mathrm{sEH}$ inhibition would attenuate CHF, especially the form associated with evident renal dysfunction (Kopkan et al. 2012, Kujal et al. 2014, Neckář et al. 2012, Sporková et al. 2011).

The rat with aorto-caval fistula (ACF) presents a well-defined model of $\mathrm{CHF}$ due to volume overload. It is characterized by cardiac remodeling, congestion, and marked activation of the intrarenal RAS with impairment of renal function; the model has many features similar to untreated human CHF and is recommended by American Heart Association (Abasi et al. 2011, Benes et al. 2011, Červenka et al. 2015a, Houser et al. 2012, Melenovsky et al. 2012). The Ren-2 transgenic rat model (TGR) combines endogenous activation of the RAS and hypertension (Jacinto et al. 1999, Kopkan et al. 2005, Kujal et al. 2014, Mullins et al. 1990, Neckáŕ et al. 2012) and we found recently that both TGR and normotensive Hannover Sprague-Dawley (HanSD) rats (transgenenegative control to TGR) with ACF-induced $\mathrm{CHF}$ exhibited tissue EETs deficiency that could be corrected by chronic sEH inhibition (Červenka et al. 2015a, Červenka et al. 2015b). Surprisingly, chronic sEH inhibition improved the survival rate and attenuated renal dysfunction in ACF TGR but not in ACF HanSD rats (Červenka et al. 2015a, Červenka et al. 2015b). These data suggested that in contrast to their important role in ACF TGR, EETs are not involved in the development of renal dysfunction in the control strain. It should be noted that while natriuretic actions of EETs have been widely investigated and are shown to underlie hypotensive and organ-protective effects (Elmarakby 2012, Fan et al. 2015, Kopkan et al. 2012, Kujal et al. 2014, Neckář et al. 2012), the role of their direct vasodilatory influence is not well known despite the evidence of such effects on the renal vasculature (Fan et al. 2015). It was found that EETs elicited markedly greater renal vasodilatation in spontaneously hypertensive rats (SHR) than in normotensive controls (Pomposiello et al. 2003). In this context we hypothesized that the vasculature of the kidney of ACF TGR exhibits increased vasodilatory responsiveness to EETs as compared to ACF HanSD rats. Therefore, such enhanced responsiveness of small renal arteries to EETs could account for the beneficial effects of chronic $\mathrm{sEH}$ inhibition on the development of renal dysfunction and progression of CHF in ACF TGR.

To test this hypothesis, we examined vasodilatory responses of interlobar arteries from the kidneys of ACF TGR and ACF HanSD rats to the newly developed 14,15-EET analog [disodium (S)-2-(13-(3pentyl)ureido)-tridec-8(Z)-enamido)succinate, EET-A] (Falck et al. 2009, Khan et al. 2014). Furthermore, to determine whether possible altered renal vasodilatory responses in ACF TGR is specific to EET-A or rather reflects general changes in vascular reactivity, the renal vascular responsiveness to norepinephrine and to acetylcholine were also examined. 


\section{Methods}

\section{Ethical approval and animals}

The studies were performed in accordance with guidelines and practices established by the Animal Care and Use Committee of the Institute for Clinical and Experimental Medicine, Prague, which accord with the European Convention on Animal Protection and Guidelines on Research Animal Use. All animals used in the present study were bred at the Center of Experimental Medicine of this Institute, from stock animals supplied by the Max Delbrück Center for Molecular Medicine, Berlin, Germany, which is accredited by the Czech Association for Accreditation of Laboratory Animal Care. Heterozygous TGR were generated by breeding male homozygous TGR with female homozygous HanSD rats and age-matched HanSD rats served as controls. The animals were kept on a 12-hour/12-hour light/dark cycle. Throughout the experiments rats were fed a normal salt, normal protein diet $(0.45 \% \mathrm{NaCl}, 19-21 \%$ protein $)$ manufactured by SEMED (Prague, Czech Republic) and had free access to tap water.

\section{CHF model}

Male rats at the initial age of 9 weeks were anesthetized (tiletamine + zolazepam, Virbac SA, Carros Cedex, France, $8 \mathrm{mg} / \mathrm{kg}$; and xylasine, Spofa, Czech Republic, $4 \mathrm{mg} / \mathrm{kg}$ intramuscularly) and CHF was induced by volume overload induced by creation of ACF using a needle technique as originally described by Garcia and Diebold (1990) and validated by many investigators including our own group (Abasi et al. 2011, Benes et al. 2011, Brower et al. 1996, Červenka et al. 2015a, Červenka et al. 2015b, Melenovsky et al. 2012). Briefly, after exposure of the abdominal aorta and inferior vena cava between the origin of the renal arteries and iliac bifurcation, the aorta was temporarily occluded for about $40 \mathrm{sec}$. An 18-gauge needle (diameter $1.2 \mathrm{~mm}$ ) was inserted into the aortic lumen and advanced across the wall into the inferior vena cava to create ACF. The needle was withdrawn and the puncture was sealed with cyanoacrylate tissue glue. The creation of ACF was confirmed by the pulsatile flow of oxygenated blood into the vena cava from abdominal aorta. Sham-operated rats underwent the identical procedure, but without creating ACF.

Series 1: Evaluation of basal cardiac function variables, blood pressure and organ weights

In this series animals that underwent either sham-operation or ACF creation as described above were left without treatment for 5 weeks. Previous, including our recent, studies have shown that 5-10 weeks after ACF induction, cardiac remodeling and renal functional characteristics typical for CHF become apparent (Abasi et al. 2011, Benes et al. 2011, Brower et al. 1996, Červenka et al. 2015a, Červenka et al. 2015, Melenovsky et al. 2012). In the present study, we intentionally shortened the period to 5 weeks, because we had shown that CHF characteristics in TGR are developed by week 5 after ACF induction, at the time when both ACF TGR and ACF HanSD rats exhibit the features of compensated CHF (Červenka et al. 2015a, Červenka et al. 2015b).

The following experimental groups were investigated:

1) Sham-operated HanSD rats $(n=8)$

2) Sham-operated TGR $(n=8)$

3) ACF HanSD rats $(n=12)$

4) ACF TGR (n=13)

At the end of experimental protocol (i.e. 5 week after sham-operation or induction of ACF) animals were anesthetized by intraperitoneal (i.p.) administration of ketamine/midazolam combination ( $50 \mathrm{mg}$ and $5 \mathrm{mg} / \mathrm{kg}$ of body weight, respectively) and echocardiography was performed as described in our recent studies (Benes et al. 2011, Červenka et al. 2015a, Červenka et al. 2015b, Neckár et al. 2012). Subsequently, the right carotid artery was cannulated and mean arterial pressure was directly assessed for $10 \mathrm{~min}$. At the end of experiments, the rats were killed with an excess i.p. dose of sodium thiopental. The hearts, kidneys, lungs and livers were excised and weighed.

Series 2: In vitro preparation and evaluation of vascular diameter responses of small renal arteries in vitro

Animals that underwent either sham-operation or ACF creation as described above were left without treatment for 5 weeks. Animals were killed by an overdose of thiopental sodium. The kidney was flushed, removed and placed in ice-cold physiological solution. Subsequently, the vessels were prepared as described in detail previously (Sporková et al. 2016). Briefly, the kidney was cut longitudinally into two to three sections from which interlobar arteries were dissected, isolated and cleared of adhering tubules and connective tissue. The outer diameter of the vessels was approximately $300 \mu \mathrm{m}$, which is characteristic for renal interlobar arteries (Kriz and Kaissling 2000). After dissection, the arteries were cannulated with glass micropipettes in a pressure myograph chamber (Danish Myograph Company). The 
cannulated vessels were perfused with Krebs solution of the following composition (in $\mathrm{mM}$ ): $117 \mathrm{NaCl}, 4.7 \mathrm{KCl}$, $2.5 \mathrm{CaCl}_{2}, \quad 1.2 \mathrm{MgCl}_{2}, \quad 1.2 \mathrm{NaH}_{2} \mathrm{PO}_{4}, 25 \mathrm{NaHCO}_{3}$ and

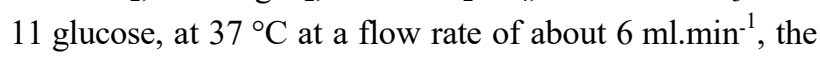
infusate was continuously oxygenated with a mixture of $95 \%$ oxygen and $5 \%$ carbon dioxide. Subsequently, the mounted arteries were slowly pressurized to reach the intravascular pressure of $80 \mathrm{mmHg}$ and equilibrated. The output of a black-and-white video camera attached to the microscope was fed to a frame grabber card mounted in a personal computer. Video images were analyzed using MioVIEW data acquisition software that continuously acquires the diameter measurements of the blood vessel. Drugs were added externally via superfusing Krebs solution. The effects of EET-A, acetylcholine and norepinephrine on the vascular diameter were determined after the vessels had been preconstricted by submaximal concentration of phenylephrine (PE) (0.3-1.0 $\mu \mathrm{M})$. In our previous study and again in the present preliminary experiments we found that the constriction produced by phenylephrine was more stable and reproducible compared to that produced by ANG II (Sporkova et al. 2016). Only one well-reacting artery from one animal was used in each experiment. In one vessel only one dose-response curve was performed, which usually took one hour. After performing wash-out procedure of the employed drug, the same vessel was used for a dose-response curve for acetylcholine. This procedure was validated and standardized in our lab as described in our recent study (Sporkova et al. 2016). Artery vasodilatory responses are expressed as percent dilation of PE-preconstricted vessels. In the case of norepinephrine the percentage of constriction was calculated from the basal relaxed diameter. Halfmaximal effective agonist concentration $\left(\mathrm{EC}_{50}\right)$ and maximal dilatory or constrictor responses (Emax) were calculated from least squares fit of the individual agonist concentration-response curves using the following logistic function from Origin 8.5:

$$
\mathrm{Y}=\left\{[\mathrm{Emin}-\operatorname{Emax}] /\left[1+\left(\mathrm{x} / \mathrm{EC}_{50}\right)_{\mathrm{n}}\right]+\operatorname{Emax}\right.
$$

where Emin is the minimum response and was constrained to zero, and $\mathrm{n}$ is the slope factor.

The major advantage of the EET-A analog is, compared to native EETs is, that it is resistant to oxidation and degradation by sEH (Falck et al. 2009, Khan et al. 2014). EET-A was synthesized by Professor Falck's group as described previously (Falck et al. 2009, Khan et al. 2014). All other chemicals were purchased from Sigma-Aldrich Company.

The following experimental groups were investigated:

1) Sham-operated HanSD rats $(n=8)$

2) Sham-operated TGR $(n=7)$

3) ACF HanSD rats $(n=9)$

4) ACF TGR $(n=9)$

\section{Statistical Analysis}

All values are expressed as means \pm SEM. Graph-Pad Prism software (Graph Pad Software, San Diego, CA, USA) was used for statistical calculations. The differences between groups for $\mathrm{E}_{\max }$ and $\mathrm{EC}_{50}$ were assessed by Student's two-tailed unpaired $t$-test. Values exceeding the $95 \%$ probability limits $(P<0.05)$ were considered statistically significant.

\section{Results}

Series 1: Evaluation of basal cardiac function variables, blood pressure and organ weights

As summarized in Table 1, sham-operated TGR exhibited significant cardiac hypertrophy [expressed as heart weight (HW) to body weight (BW) ratio] as compared with sham-operated HanSD rats. ACF HanSD rats and ACF TGR showed marked increases in HW/BW as compared with sham-operated rats, but this increase was more pronounced in ACF TGR. ACF HanSD rats as well as ACF TGR exhibited increases in the cardiac output (dependent on the presence of the shunt), significant decreases in left ventricle (LV) fractional shortening (indicative of LV systolic dysfunction) and significant increases in LV and right ventricle (RV) diameters as compared with the sham-operated counterparts, notably, the increases in LV and RV diameters were more pronounced in ACF TGR as compared with ACF HanSD rats. In addition, ACF TGR displayed significantly higher ratio of lung weight to $\mathrm{BW}$ as compared with shamoperated TGR (indicating the development of important lung congestion in ACF TGR), but there were not significant differences between experimental groups in kidney and liver weight when normalized to BW. Taken together, these findings indicate that 5 weeks after creation of ACF the untreated ACF HanSD rats as well as ACF TGR are still at the stage of compensated CHF, which is in accordance with our recent findings (Červenka et al. 2015a, Červenka et al. 2015b), but our present data also suggest that ACF TGR exhibit signs indicating that soon afterwards they will progress toward the decompensated 
phase of CHF (based on parameters such as LV and RV diameters, cardiac hypertrophy and especially the increased lung weight to BW ratio), similarly as we reported recently (Červenka et al. 2015b).

Table 1. Basal characteristics of cardiac function, organ weights and blood pressure at week 5 after induction of aorto-caval fistula or sham-operation.

\begin{tabular}{|c|c|c|c|c|}
\hline \multirow[b]{2}{*}{ Parameter } & \multicolumn{4}{|c|}{ Group } \\
\hline & $\begin{array}{c}\text { Sham-operated } \\
\text { HanSD }\end{array}$ & $\begin{array}{c}\text { Sham-operated } \\
\text { TGR }\end{array}$ & ACF HanSD & ACF TGR \\
\hline Heart rate $\left(s^{-1}\right)$ & $384 \pm 26$ & $392 \pm 18$ & $332 \pm 16^{\#}$ & $328 \pm 22^{\#}$ \\
\hline$L V$ diastolic diameter $(\mathrm{mm})$ & $6.28 \pm 0.36$ & $6.36 \pm 0.28$ & $8.96 \pm 0.54^{\#}$ & $10.62 \pm 0.36^{\# @}$ \\
\hline LV systolic diameter $(\mathrm{mm})$ & $3.14 \pm 0.23$ & $3.27 \pm 0.25$ & $6.36 \pm 0.18^{\#}$ & $7.24 \pm 0.22^{\# @ ~}$ \\
\hline$R V$ diastolic diameter $(\mathrm{mm})$ & $3.62 \pm 0.21$ & $3.48 \pm 0.27$ & $4.57 \pm 0.22^{\#}$ & $6.68 \pm 0.29^{\# @}$ \\
\hline LV fractional shortening (\%) & $54 \pm 3$ & $52 \pm 3$ & $36 \pm 3^{\#}$ & $35 \pm 2^{\#}$ \\
\hline Cardiac output $(\mathrm{ml} / \mathrm{min})$ & $106 \pm 17$ & $114 \pm 19$ & $368 \pm 21^{\#}$ & $372 \pm 25^{\#}$ \\
\hline $\begin{array}{l}\text { Mean arterial pressure } \\
(\mathrm{mmHg})\end{array}$ & $119 \pm 6$ & $142 \pm 5 *$ & $88 \pm 4^{\#}$ & $105 \pm 6^{\# @}$ \\
\hline Body weight (g) & $482 \pm 28$ & $496 \pm 18$ & $506 \pm 24$ & $512 \pm 23$ \\
\hline $\begin{array}{l}\text { Heart weight }(\mathrm{mg}) / \text { Body } \\
\text { weight }(\mathrm{g})\end{array}$ & $3.21 \pm 0.14$ & $4.08 \pm 0.19 *$ & $4.74 \pm 0.17^{\#}$ & $6.01 \pm 0.22^{\# @}$ \\
\hline $\begin{array}{l}\text { Kidney weight (mg)/Body } \\
\text { weight }(g)\end{array}$ & $2.59 \pm 0.17$ & $2.48 \pm 0.19$ & $2.61 \pm 0.22$ & $2.63 \pm 0.24$ \\
\hline $\begin{array}{l}\text { Lung weight (mg)/Body } \\
\text { weight }(g)\end{array}$ & $3.68 \pm 0.31$ & $3.72 \pm 0.34$ & $4.29 \pm 0.41$ & $4.86 \pm 0.29^{\#}$ \\
\hline $\begin{array}{l}\text { Liver weight (mg)/Body } \\
\text { weight }(g)\end{array}$ & $29.2 \pm 0.88$ & $28.9 \pm 0.91$ & $29.6 \pm 0.85$ & $30.4 \pm 1.22$ \\
\hline
\end{tabular}

Values are means $\pm \mathrm{SEM}$. HanSD, transgene-negative Hannover-Sprague Dawley rats; TGR, Ren-2 renin transgenic rats; ACF, aortocaval fistula; EET-A, 14,15-EETs agonistic analog; LV, RV, left and right ventricle, respectively. $* P<0.05$ sham-operated TGR vs. shamoperated HanSD rats; ${ }^{\#} P<0.05$ ACF rats vs. sham-operated rats (always comparing the same strain). ${ }^{\circledR} P<0.05$ ACF TGR vs. ACF HanSD rats.

As summarized in Table 2, there were no significant differences in the basal outer diameter of isolated interlobar arteries between sham-operated and ACF TGR and HanSD rats. These diameter values refer to the interlobar arteries in rats (Kriz and Kaissling 2000). It is now recognized that these arteries act as resistance vessels playing important role in autoregulation of the renal blood flow and glomerular filtration rate during changes in renal perfusion pressure (Carlstrom et al. 2015). As summarized in Table 2, application of $1.0 \mu \mathrm{M}$ phenylephrine (PE) produced stable constriction in all experimental groups.

Figure 1 summarizes the responses of PE-preconstricted renal interlobar arteries to acetylcholine in all experimental groups.

As shown in Figures $1 \mathrm{~A}$ and $1 \mathrm{~B}$, arteries from sham-operated TGR and HanSD rats responded to application of acetylcholine with dose-dependent vasodilatation, however, in the HanSD rats the descending slope of the curve was significantly steeper (half maximal effective concentration (EC50) are in Table 2). Moreover, the maximal dilatory response $\left(E_{\max }\right)$ was significantly reduced in the arteries of sham-operated TGR as compared with sham-operated HanSD rats (Table 2).

There was no significant difference in the vasodilatory responses to acetylcholine between the arteries of sham-operated HanSD rats and ACF HanSD rats (Fig. 1). Likewise, acetylcholine elicited similar vasodilatory responses in the arteries of sham-operated TGR and ACF TGR (Fig. 1B). 
Table 2. Maximal vasodilatory and vasoconstrictor responses $\left(E_{\max }\right)$ and half maximal effective concentration (EC50) to produce vascular responses of phenylephrine-preconstricted renal interlobar arteries.

\begin{tabular}{|c|c|c|c|c|}
\hline \multirow[b]{2}{*}{ Parameter } & \multicolumn{4}{|c|}{ Group } \\
\hline & $\begin{array}{c}\text { Sham-operated } \\
\text { HanSD } \\
(\mathbf{n}=\mathbf{8})\end{array}$ & $\begin{array}{c}\text { Sham-operated } \\
\text { TGR } \\
(n=7)\end{array}$ & $\begin{array}{c}\text { ACF HanSD } \\
(\mathrm{n}=9)\end{array}$ & $\begin{array}{c}\text { ACF TGR } \\
(\mathbf{n}=9)\end{array}$ \\
\hline Basal diameter ( $\mu \mathrm{m})$ & $342 \pm 13$ & $324 \pm 14$ & $327 \pm 16$ & $330 \pm 17$ \\
\hline $\begin{array}{l}\text { PE-preconstricted } \\
\text { diameter }(\mu \mathrm{m})\end{array}$ & $269 \pm 12$ & $251 \pm 11$ & $247 \pm 13$ & $260 \pm 11$ \\
\hline $\begin{array}{l}\text { PE-elicited changes in } \\
\text { diameter }(\%)\end{array}$ & $-21.4 \pm 6.1$ & $-22.5 \pm 7.1$ & $-24.5 \pm 5.9$ & $-21.2 \pm 4.4$ \\
\hline \multicolumn{5}{|l|}{ Acetylcholine } \\
\hline$E_{\max }(\%)$ & $108 \pm 7$ & $64 \pm 6^{*}$ & $85 \pm 9$ & $61 \pm 7^{\#}$ \\
\hline$E C 50(n M)$ & $289 \pm 62$ & $549 \pm 63 *$ & $408 \pm 91$ & $863 \pm 62^{\#}$ \\
\hline \multicolumn{5}{|l|}{ Norepinephrine } \\
\hline$E_{\max }(\%)$ & $58 \pm 3$ & $46 \pm 4$ & $53 \pm 3$ & $48 \pm 3$ \\
\hline$E C 50(n M)$ & $998 \pm 64$ & $361 \pm 49$ & $601 \pm 54$ & $280 \pm 50$ \\
\hline \multicolumn{5}{|l|}{ EET-A } \\
\hline$E_{\max }(\%)$ & $27 \pm 4$ & $22 \pm 5$ & $35 \pm 3$ & $16 \pm 3^{\#}$ \\
\hline$E C 50(n M)$ & $124 \pm 24$ & $100 \pm 18$ & $212 \pm 31$ & $98 \pm 12^{\#}$ \\
\hline
\end{tabular}

Values are means \pm SEM. HanSD, transgene-negative Hannover-Sprague Dawley rats; TGR, Ren-2 renin transgenic rats; ACF, aortocaval fistula; EET-A, 14,15-EETs agonistic analog; $* P<0.05$ sham-operated TGR vs. sham-operated HanSD rats; ${ }^{*} P<0.05$ ACF TGR vs. ACF HanSD rats.

On the whole, it is evident from Figures $1 \mathrm{~A}$ and 1B that PE-preconstricted renal interlobar arteries from ACF TGR showed reduced vasodilatory responses to acetylcholine as compared to arteries of ACF HanSD rats, and, again, $\mathrm{E}_{\max }$ was lower in ACF TGR as compared with ACF HanSD rats (Table 2).

Figure 2 summarizes the response of renal interlobar arteries to norepinephrine in all experimental groups (HanSD sham or with ACF, and TGR sham or with $\mathrm{ACF}$ ) and shows that norepinephrine induced similar dose-dependent vasoconstriction in each group; nor were there any significant between-group differences in $\mathrm{E}_{\max }$ (Table 2).

Figure 3 summarizes responses of the PE-preconstricted renal interlobar arteries to administration of EET-A in each of the four experimental groups. The arteries from sham-operated TGR and HanSD rats responded to application of EET-A by similar dose-dependent vasodilatation, however, it is emphasized that vasodilatory responses to EET-A were significantly smaller than those observed in response to acetylcholine (Fig. 1 and EC50 and $\mathrm{E}_{\max }$ values in Table 2).
There were no significant differences in vasodilatory responses to EET-A in the arteries of shamoperated HanSD rats and ACF HanSD rats (Fig. 3A). Likewise, EET-A caused similar vasodilatory responses in the arteries of sham-operated TGR and ACF TGR (Fig. 3B).

On the whole, it is evident from the data of Figure 3 that PE-preconstricted renal interlobar arteries from ACF TGR showed reduced vasodilatory responses to EET-A as compared to arteries of ACF HanSD rats, which was in agreement with lower $\mathrm{E}_{\max }$ in ACF TGR as compared with ACF HanSD rats (Table 2).

\section{Discussion}

The first critically important finding of the present study is that renal interlobar arteries isolated from the kidneys of ACF HanSD rats in the phase when all characteristics of CHF have fully developed (Červenka $e t$ al. 2015a) exhibit greater vasodilator responses to EET-A compared to arteries from kidneys of ACF TGR.

These findings are in disagreement with our 
hypothesis suggesting that increased vasodilatory responsiveness of small renal arteries to EETs in ACF TGR could account for the beneficial actions of chronic sEH inhibition on the course CHF in this strain. Moreover, our results show that vasodilatory responses to acetylcholine in ACF HanSD were also greater compared

A O Sham-operated HanSD $\square$ ACF HanSD



B

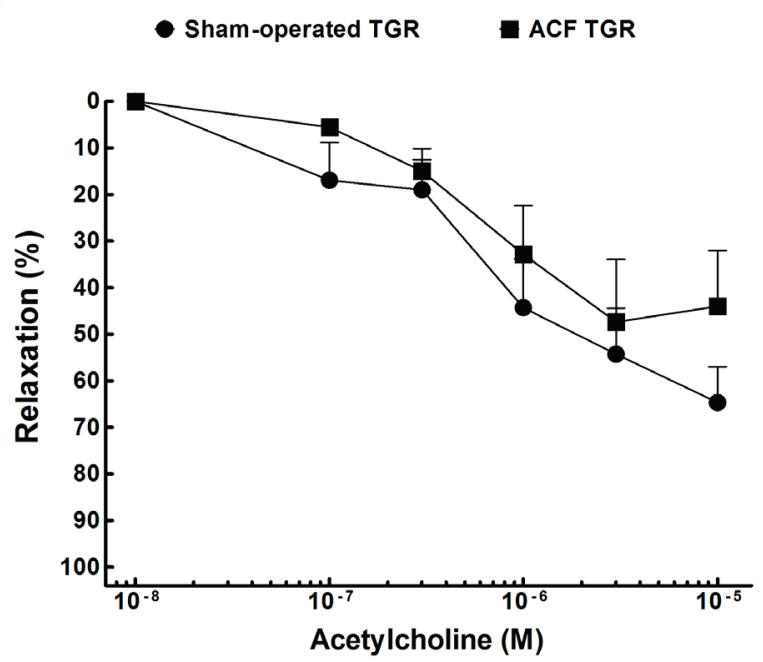

Fig 1. Vasodilator effects of acetylcholine in phenylephrinepreconstricted renal interlobar arteries isolated from kidneys of sham-operated heterozygous Ren-2 renin transgenic rats (TGR), sham operated transgene-negative Hannover Sprague-Dawley (HanSD) rats and in TGR and HanSD rats with aorto-caval fistula (ACF).

Our original hypothesis was also based on findings showing that EETs elicited markedly greater renal vasodilatation in SHR than in WKY, and also vasodilatory actions of EETs analogs in ANG II-infused hypertensive animals were augmented compared to normotensive controls. Therefore, we were at first to ACF TGR rats. This suggests that some general dysregulation of the mechanisms contributing to attenuated hyperpolarization of vascular smooth muscle cells might occur in the resistance vessels of ACF TGR, resulting in decreased vasorelaxation in response to various dilatory agents.

A O Sham-operated HanSD $\square$ ACF HanSD

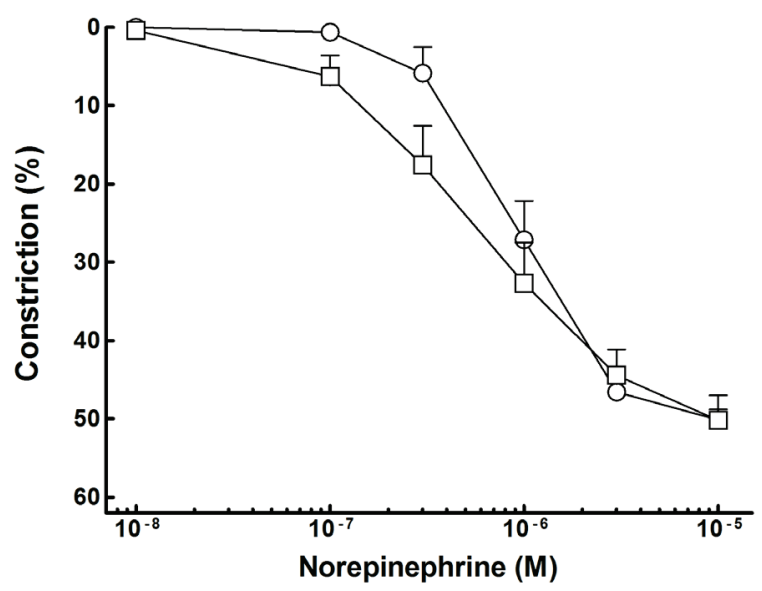

B

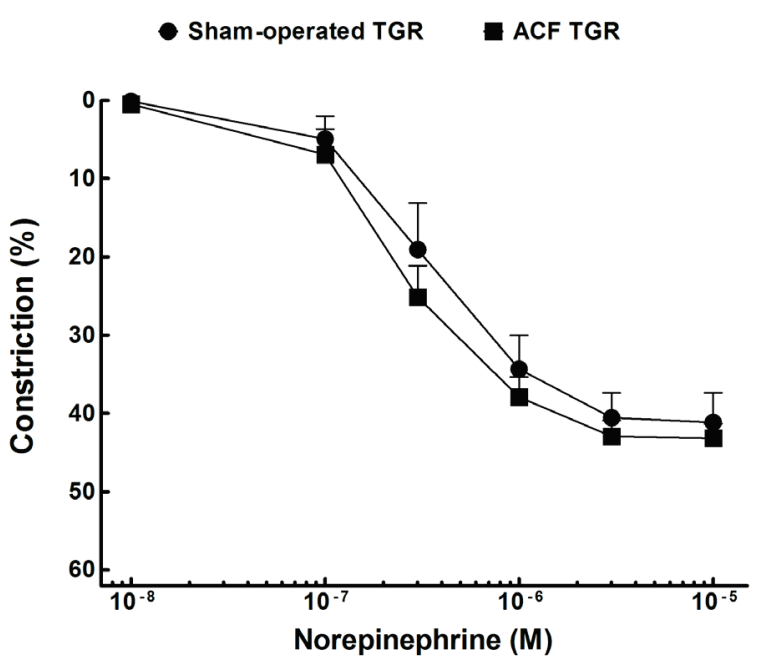

Fig 2. Vasoconstrictor effects of norepinephrine in phenylephrine-preconstricted renal interlobar arteries isolated from kidneys of sham-operated heterozygous Ren-2 renin transgenic rats (TGR), sham operated transgene-negative Hannover Sprague-Dawley (HanSD) rats and in TGR and HanSD rats with aorto-caval fistula (ACF).

inclined to share the view that hypertensive animals and human subjects (Ellinsworth et al. 2016, Fan et al. 2015, Khan et al. 2014) and also our ACF TGR should exhibit increased vasodilatory responsiveness to EETs compared to ACF HanSD rats. However, this hypothesis proved incompatible with the data of our previous study which 
A O Sham-operated HanSD $\square$ ACF HanSD

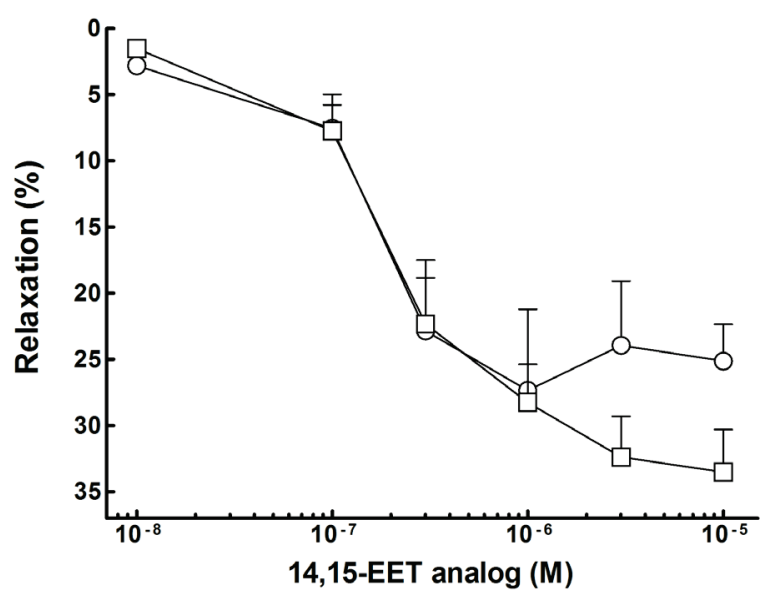

B

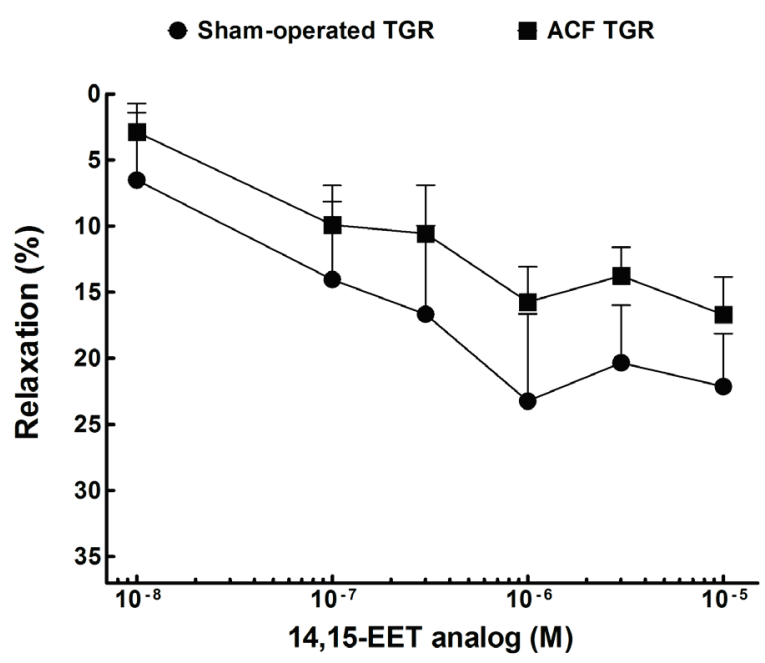

Fig. 3. Vasodilator effects of 14,15-epoxyeicosatrienoic acid analog in phenylephrine-preconstricted renal interlobar arteries isolated from kidneys of sham-operated heterozygous Ren-2 renin transgenic rats (TGR), sham operated transgene-negative Hannover Sprague-Dawley (HanSD) rats and in TGR and HanSD rats with aorto-caval fistula (ACF).

showed that small renal arteries of the nonclipped kidneys of two-kidney, one-clip (2K1C) Goldblatt hypertensive rats exhibit vasodilator responses to EETs that are distinctly reduced compared to those of the arteries from sham-operated normotensive rats (Sporková et al. 2016). In addition, our present results show that renal interlobar arteries isolated from the kidneys of sham-operated TGR exhibited vasodilator responses to EET-A similar with those in sham-operated HanSD rats. This finding,, again, puts to doubt the notion about enhanced vasodilatory responsiveness of hypertensive animals, at least of TGR and $2 \mathrm{~K} 1 \mathrm{C}$ rats i.e. two different models of ANG II-dependent hypertension. Moreover, we found that the renal interlobar arteries from shamoperated TGR and HanSD rats as well as from ACF TGR and HanSD rats showed a similar response pattern to norepinephrine, suggesting that, in general, animals with ACF-induced CHF do not exhibit any alterations in the renal vascular responsiveness to vasoactive agents. These findings are in agreement with previous in vivo studies showing that TGR do not show any generalized increase in vascular responsiveness to endogenous vasoconstrictors with the exception of an exaggerated renal and peripheral vascular responsiveness to ANG II (Jacinto et al. 1999, Kopkan et al. 2005).

On the whole, based on the present findings and considering the earlier relevant evidence, we suggest that enhanced vasodilatory responsiveness of small renal arteries to EETs is not responsible for the beneficial actions of chronic sEH inhibition on the development of renal functional impairment and progression of $\mathrm{CHF}$ in ACF TGR.

In this context, the second critically important finding of the present study is that, in general, renal vasodilatory responses to EET-A observed in sham-operated TGR and sham-operated HanSD rats as well as in ACF TGR and ACF HanSD rats were substantially smaller than the responses to acetylcholine (compare the data of Figures 1 and 3 and see $E_{\max }$ values for EET-A and acetylcholine in Table 2). Our present results are in agreement with our recent findings showing that in the nonclipped kidneys of $2 \mathrm{~K} 1 \mathrm{C}$ and in shamoperated normotensive rats, vasodilatory responses to EET-A, to a native 14,15-EET and to 11,12-ether-EET8ZE (an analog of 11,12-EET) were rather modest (Sporková et al. 2016). These findings indicate that contribution of renal vasodilatory effects of EETs to the improvement of renal function in ACF-induced CHF is minor if any, strongly suggesting that direct renal tubular effects of EETs on sodium and water reabsorption is likely the main mechanism underlying improvement of renal function in ACF TGR treated with a SEH inhibitor. This interpretation is supported by the evidence that deficiency in natriuretic actions of EETs importantly contributes to the pathophysiology of many forms of experimental hypertension and progression of chronic kidney diseases. Indeed, most of available evidence suggests that EETs' antihypertensive and organ-protective properties are mainly associated with their action on sodium excretion (Elmarakby 2012, Fan et al. 2015, Khan et al. 2014, Kopkan et al. 2012, Kujal et al. 2014, Neckáŕ et al. 2012, Sporkova et al. 2011). 
In conclusion, our present results show that small renal arteries of the kidneys of ACF HanSD rats exhibit greater vasodilator responses to EET-A compared to the arteries of ACF TGR. Therefore, reduced renal vasodilatory actions of EETs cannot be responsible for the lack of beneficial effects of chronic sEH inhibition on the development of renal dysfunction and progression of CHF in ACF HanSD rats.

\section{Conflict of Interest}

There is no conflict of interest.

\section{Acknowledgements}

This study was primary supported by the grant No. P30315-07544S awarded to Z.H. by the Czech Science Foundation (GAČR). A.S. was supported by a Marie Curie Fellowship from the European Commission Program PEOPLE (IRG 247847). L.Č. is supported by Ministry of Health of the Czech Republic within the project for the development of research organization 00023001 (IKEM) - institutional support.

\section{References}

ABASSI Z, GOLTSMNA I, KARRAM T, WINAVER J, HOFFMAN A: Aortocaval fistula in rat: a unique model of volume-overload congestive heart failure and cardiac hypertrophy. J Biomed Biotechnol 2011: 729497, 2011.

BENES J, KAZDOVA L, DRAHOTA Z, HOUSTEK J, MEDRIKOVA D, KOPECKY J, KOVAROVA N, VRBACKY M, SEDMERA D, STRNAD H, KOLAR M, PETRAK J, BENADA O, SKAROUPKOVA P, CERVENKA L, MELENOVSKY V: Effect of metformin therapy on cardiac function and survival in a volume-overload model of heart failure in rats. Clin Sci 129: 29-41, 2011.

BRAAM B, JOLES JA, DANISHWAR AH, GAILLARD CA: Cardiorenal syndrome - current understanding and future perspectives. Nat Rev Nephrol 10: 48-55, 2014.

BRAUNWALD E: The war against heart failure: the Lancet lecture. Lancet 385: 812-824, $2015 \mathrm{a}$.

BRAUNWALD E: The path to an angiotensin receptor antagonist-neprilysin inhibitor in the treatment of heart failure. J Am Coll Cardiol 65: 1029-1041, 2015b.

BROWER GL, HENEGAR JR, JANICKI JS: Temporal evaluation of left ventricular remodeling and function in rats with chronic volume overload. Am J Physiol 40: H2071-H2078, 1996.

CAPDEVILA JH, WANG W, FALCK JR: Arachidonic acid monooxygenase: genetic and biochemical approaches to physiological/pathophysiological relevance. Prostaglandins Other Lipid Mediat 120: 40-49, 2015.

CARLSTROM M, WILCOX CS, ARENDSHORST WJ: Renal autoregulation in health and disease. Physiol Rev 95 : 405-411, 2015.

COHEN-SEGEV R, FRANCIS B, ABU-SALEH N, AWAD H, LAZAROVICH A, KABALA A, ARONSON D, ABASSI $\mathrm{Z}$ : Cardiac and renal distribution of ACE and ACE-2 in rats with heart failure. Acta Histochem 116: 1342-1349, 2014.

ČERVENKA L, MELENOVSKÝ V, HUSKOVÁ Z, SPORKOVÁ A, BURGELOVÁ M, ŠKAROUPKOVÁ P, HWANG SH, HAMMOCK BD, IMIG JD, SADOWSKI J: Inhibition of soluble epoxide hydrolase does not improve the course of congestive heart failure and the development of renal dysfunction in rats with volume overload induced by aorto-caval fistula. Physiol Res 64: 857-873, 2015a.

ČERVENKA L, MELENOVSKÝ V, HUSKOVÁ Z, ŠKAROUPKOVÁ P, NISHIYAMA A, SADOWSKI J: Inhibition of soluble epoxide hydrolase counteracts the development of renal dysfunction and progression of congestive heart failure in Ren-2 transgenic hypertensive rats with aorto-caval fistula Clin Exp Pharmacol Physiol 42: 795-807, 2015b.

ELLINSWORTH DC, SANDOW SL, SHUKLA N, LIU Y, JEREMY JY, GUTTERMAN DD: Endothelium-derived hyperpolarization and coronary vasodilatation: diverse and integrated roles of epoxyeicosatrienoic acids, hydrogen peroxide, and gap junctions. Microcirculation 23: 15-32, 2016.

ELMARAKBY AA: Reno-protective mechanisms of epoxyeicosatrienoic acids in cardiovascular disease. Am J Physiol Regul Integr Comp Physiol 302: R321-R330, 2012. 
FALCK JR, KODELA R, MANNE R, ATCHA KR, PULI N, DUBASI N, MANTHATI VL, CAPDEVILA JH, YI XY, GOLDMAN DH, MORISSEAU C, HAMMOCK BD, CAMPBELL WB: 14,15-epoxyeicosa-5,8,11-trienoic acid (14,15-EET) surrogates containing epoxide bioisosteres: influence upon vascular relaxation and soluble epoxide hydrolase inhibition. J Med Chem 52: 5069-5075, 2009.

FAN F, MUROYA Y, ROMAN RJ: Cytochrome P450 eicosanoids in hypertension and renal disease. Curr Opin Nephrol Hypertens 24: 37-46, 2015.

GARCIA R, DIEBOLD S: Simple, rapid, and effective method of producing aortocaval shunts in the rat. Cardiovasc Res 24: 430-432, 1990.

HOUSER SR, MARGULIES KB, MURPHY AM, SPINALE FG, FRANCIS GS, PRABHU SD, ROCKMAN HA, KASS DA, MOLKENTIN JD, SUSSMAN MA, KOCH WJ: Animals models of heart failure. a scientific statement from the American Heart Association. Circ Res 111: 131-150, 2012.

IMIG JD, DEICHMANN PC: Afferent arteriolar responses to ANG II involve activation of PLA 2 and modulation by lipoxygenase and P-450 pathways. Am J Physiol 273: F274-F282, 1997.

IMIG JD, ZHAO X, FALCK JR, WEI S, CAPDEVIALL JH. Enhanced renal microvascular reactivity to angiotensin II in hypertension is ameliorated by the sulfonamide analog of 11,12-epoxyeicosatrienoic acid. J Hypertens 19 : 983-992, 2001.

ICHIKAWA I, PFEFFER JM, FEFFER MA, HOSTETTER TH, BRENNER BM: Role of angiotensin II in the altered renal function of congestive heart failure. Circ Res 55: 669-675, 1984.

IWAZ JA, LEE E, ARAMIN H, ROMERO D, IQBAL N, KAWAHARA M, KHUSRO F, KNIGHT B, PATEL MV, SHARMA S, MAISEL AS: New targets in the drug treatment of heart failure. Drugs 76: 187-201, 2016.

JACINTO SM, MULLINS JJ, MITCHELL KD: Enhanced renal vascular responsiveness to angiotensin II in hypertensive Ren-2 transgenic rats. Am J Physiol 276: F315-F322, 1999.

KHAN MAH, PAVLOV TS, CHRISTAIN SV, NECKÁŘ J, STARUSCHENKO A, GAUTHIER KM, CAPDEVILLA JH, FALCK JR, CAMPBELL WB, IMIG JD: Epoxyeicosatrienoic acid analogue lowers blood pressure through vasodilatation and sodium channel inhibition. Clin Sci 127: 463-474, 2014.

KOHAGURE K, ENDO Y, ITO O, ARIMA S, OMATA K, ITO S: Endogenous nitric oxide and epoxyeicosatrienoic acids modulate angiotensin II-induced constriction in the rabbit afferent arteriole. Acta Physiol Scand 168: 107-112, 2000.

KOPKAN L, KRAMER HJ, HUSKOVÁ Z, VAŇOURKOVÁ Z, ŠKAROUPKOVÁ P, THUMOVÁ M, ČERVENKA $\mathrm{L}$ : The role of intrarenal angiotensin II in the development of hypertension in Ren-2 transgenic rats. J Hypertens 23: 1531-1539, 2005.

KOPKAN L, HUSKOVÁ Z, SPORKOVÁ A, VARCABOVÁ Š, HONETSCHLAGEROVÁ Z, HWANG SH, TASI HJ, HAMMOCK BD, IMIG JD, KRAMER HJ, BURGELOVA M, VOJTÍŠKOVÁ A, KUJAL P, VERNEROVÁ Z, ČERVENKA L: Soluble epoxide hydrolase inhibition exhibits antihypertensive actions independently of nitric oxide in mice with renovascular hypertension. Kidney Blood Press Res 35: 595-607, 2012.

KRIZ W, KAISSLING B: Structural organization of the mammalian kidney. In: The Kidney: Physiology and Pathophysiology. SELDIN DW, GIEBISCH G (eds), Lippincott Williams \& Wilkins, Philadelphia, 2000, pp 587-654.

KUJAL P, ČERTÍKOVÁ CHÁBOVÁ V, ŠKAROUPKOVÁ P, HUSKOVÁ Z, VERNEROVÁ Z, KRAMER HJ, WALKOWSKA A, KOMPANOVSKA-JEZIERSKA E, SADOWSKI J, KITADA K, NISHIYAMA A, HWANG SH, HAMMOCK BD, IMIG JD, ČERVENKA L: Inhibition of soluble epoxide hydrolase is renoprotective in 5/6 nephrectomized Ren-2 transgenic hypertensive rats. Clin Exp Pharmacol Physiol 41: 227-237, 2014.

MADHUN ZT, GOLDHWAIT DA, MCKAY D, HOPFER U, DOUGHLAS JG: An epoxygenase metabolite of arachidonic acid mediates angiotensin II-induced rises in cytosolic calcium rabbit proximal tubule epithelial cells. J Clin Invest 88: 456-461, 1991.

MAGGIONI AP: Epidemiology of heart failure in Europe. Heart Fail Clin 11: 625-635, 2015.

MANN JF, BOHM M: Dual renin-angiotensin system blockade and outcome benefits in hypertension: a narrative review. Curr Opin Cardiol 30: 373-377, 2015. 
MELENOVSKY V, SKAROUPKOVA P, BENES J, TORRESOVA V, KOPKAN L, CERVENKA L: The course of heart failure development and mortality in rats with volume overload due to aorto-caval fistula. Kidney Blood Press Res 35: 167-173, 2012.

MULLINS JJ, PETERS J, GANTEN D: Fulminant hypertension in transgenic rat harboring the mouse Ren-2 gene. Nature 344: 541-544, 1990.

NECKÁŘ J, KOPKAN L, HUSKOVÁ Z, KOLÁŘ F, PAPOUŠEK F, KRAMER HJ, HWANG SH, HAMMOCK BD, IMIG JD, MALÝ J, NETUKA I, OŠŤÁDAL B, ČERVENKA L: Inhibition of soluble epoxide hydrolase by cis-4-[4-(3-adamantan-1-ylureido)cyclohexyl-oxy]benzoic acid exhibits antihypertensive actions in transgenic rats with angiotensin II-dependent hypertension. Clin Sci 122: 513-525, 2012.

ONUIGBO MA: RAAS inhibition and cardiorenal syndrome. Curr Hypertens Rev 10: 107-111, 2014.

PACKER M: New concepts in the pathophysiology of heart failure: beneficial and deleterious interaction of endogenous haemodynamic and neurohormonal mechanisms. J Intern Med 239: 327-333, 1996.

PFEFFER MA, PFEFFER JM, STEINBERG C, FINN P: Survival after experimental myocardial infarction: beneficial effects of long-term therapy with captopril. Circulation 72: 406-412, 1985.

POMPOSIELLO SI, QUILLEY J, CARROLL MA, FALCK JR, MCGIFF JC: 5,6-epoxyeicosatrienoic acid mediates the enhanced renal vasodilatation to arachidonic acid in the SHR. Hypertension 42: 548-554, 2003.

SAKAIRI Y, JACOBSON HR, NOLAND DT, CAPDEVILA JH, FALCK JR, BREYER MD: 5,6-EET inhibits ion transport in collecting duct by stimulating endogenous prostaglandin synthesis. Am J Physiol 268: F931-F939, 1995.

SPORKOVÁ A, KOPKAN L, VARCABOVÁ Š, HUSKOVÁ Z, HWANG SH, HAMMOCK BD, IMIG JD, KRAMER HJ, ČERVENKA L: Role of cytochrome P-450 metabolites in the regulation of renal function and blood pressure in 2-kidney, 1-clip hypertensive rats. Am J Physiol Regul Integr Comp Physiol 300: R1468-R1475, 2011.

SPORKOVÁ A, REDDY RN, FALCK JR, IMIG JD, KOPKAN L, SADOWSKI J, ČERVENKA L: Interlobular arteries from two-kidney, one-clip Goldblatt hypertensive rats exhibit impaired vasodilator response to epoxyeicosatrienoic acid. Am J Med Sci 351: 513-519, 2016.

WALKOWSKA A, ŠKAROUPKOVÁ P, HUSKOVÁ Z, VAŇOURKOVÁ Z, ČERTÍKOVÁ CHÁBOVÁ V, TESAŘ V, KRAMER HJ, FALCK JR, IMIG JD, KOMPANOWSKA-JEZIERSKA E, SADOWSKI J, ČERVENKA L: Intrarenal cytochrome P-450 metabolites of arachidonic acid in the regulation of the nonclipped kidney function in two-kidney, one-clip Goldblatt hypertensive rats. J Hypertens 28: 582-593, 2010. 